'Department of Nursing Services, Tan Tock Seng Hospital, Singapore

${ }^{2}$ Centre Hospitalier Universitaire de Québec-Hôtel-Dieu,

Departments of Medicine and

Medical Biology, Québec, Canada

${ }^{3}$ Departments of Medicine, Clinical Epidemiology, and Biostatistics, McMaster University, Hamilton,

Canada

Correspondence to: $\mathrm{E} Y$ Chan ee_yuee_chan@ttsh.com.sg

doi: 10.1136/bmi.39136.528160.BE

\title{
Oral decontamination for prevention of pneumonia in mechanically ventilated adults: systematic review and meta-analysis
}

\author{
Ee Yuee Chan, nurse educator, ${ }^{1}$ Annie Ruest, infectious diseases consultant, ${ }^{2}$ Maureen 0 Meade, associate \\ professor, $^{3}$ Deborah J Cook, professor ${ }^{3}$
}

\section{ABSTRACT}

Objective To evaluate the effect of oral decontamination on the incidence of ventilator associated pneumonia and mortality in mechanically ventilated adults.

Design Systematic review and meta-analysis.

Data sources Medline, Embase, CINAHL, the Cochrane Library, trials registers, reference lists, conference proceedings, and investigators in the specialty.

Review methods Two independent reviewers screened studies for inclusion, assessed trial quality, and extracted data. Eligible trials were randomised controlled trials enrolling mechanically ventilated adults that compared the effects of daily oral application of antibiotics or antiseptics with no prophylaxis.

Results 11 trials totalling 3242 patients met the inclusion criteria. Among four trials with 1098 patients, oral application of antibiotics did not significantly reduce the incidence of ventilator associated pneumonia (relative risk $0.69,95 \%$ confidence interval 0.41 to 1.18 ). In seven trials with 2144 patients, however, oral application of antiseptics significantly reduced the incidence of ventilator associated pneumonia (0.56, 0.39 to 0.81$)$. When the results of the 11 trials were pooled, rates of ventilator associated pneumonia were lower among patients receiving either method of oral decontamination $(0.61,0.45$ to 0.82$)$. Mortality was not influenced by prophylaxis with either antibiotics $(0.94,0.73$ to 1.21$)$ or antiseptics $(0.96,0.69$ to 1.33$)$ nor was duration of mechanical ventilation or stay in the intensive care unit. Conclusions Oral decontamination of mechanically ventilated adults using antiseptics is associated with a lower risk of ventilator associated pneumonia. Neither antiseptic nor antibiotic oral decontamination reduced mortality or duration of mechanical ventilation or stay in the intensive care unit.

\section{INTRODUCTION}

Ventilator associated pneumonia remains a leading cause of morbidity and mortality among mechanically ventilated patients, with the incidence ranging from $9 \%$ to $27 \%$ and a crude mortality that may exceed $50 \% .{ }^{1-4}$ Aspiration of bacteria from the upper digestive tract is important in the pathogenesis of this infection. ${ }^{45}$ Two different interventions aimed at decreasing the oral bacterial load are selective decontamination of the digestive tract, involving administration of nonabsorbable antibiotics by mouth and through a nasogastric tube, and oral decontamination, which is limited to topical oral application of antibiotics or antiseptics.

Previous meta-analyses of selective decontamination of the digestive tract found a significant reduction in rates of ventilator associated pneumonia among treated patients. ${ }^{6-14}$ The use of this intervention is, however, limited by concern about the emergence of antibiotic resistant bacteria. ${ }^{15-17}$ Oral decontamination alone therefore may be more attractive because it requires only a fraction of the antibiotics used in selective decontamination of the digestive tract. To date, trials of oral decontamination using antibiotics have generated conflicting results, some suggesting benefit $^{1819 \text { w1 }}$ and others showing no benefit. ${ }^{\text {w2 w3 }}$

One alternative to oral decontamination with antibiotics is to use antiseptics, such as chlorhexidine gluconate or povidone iodine. In contrast to antibiotics, antiseptics act rapidly at multiple target sites and accordingly may be less prone to induce drug resistance. ${ }^{20}$ Observational studies suggest that antiseptic oral decontamination can reduce ventilator associated pneumonia, ${ }^{2122}$ but randomised controlled trials are not convincing. ${ }^{23}$ w4-w6 Recently a meta-analysis of four trials on chlorhexidine failed to show a significant reduction in rates of ventilator associated pneumonia. ${ }^{24}$ Two subsequent randomised controlled trials, however, suggested benefit from this approach. ${ }^{\text {w7 w8 }}$

Current guidelines from the Centers for Disease Control and Prevention recommend topical oral chlorhexidine $0.12 \%$ during the perioperative period for adults undergoing cardiac surgery (grade II evidence)..$^{3}$ The routine use of antibiotic or antiseptic oral decontamination for the prevention of ventilator associated pneumonia, however, remains unresolved. ${ }^{3}$ Despite the lack of firm evidence favouring this preventive intervention, a recent survey across 59 European intensive care units from five countries showed that $61 \%$ of the respondents used oral decontamination with chlorhexidine. ${ }^{25}$ 
We carried out a systematic review and meta-analysis to estimate the effect of oral decontamination using topical antibiotics or antiseptics on ventilator associated pneumonia and mortality in mechanically ventilated adults.

\section{METHODS}

With the assistance of a professional librarian we searched for relevant randomised controlled trials using the Ovid version of Medline (1966 to May week 3,2006 ) and a maximally sensitive strategy. We modified this search for Embase (1980 to week 21, 2006) and CINAHL (1982 to May week 3, 2006). We also searched CENTRAL (the Cochrane Central Register of Controlled Trials, the Cochrane Library, issue 1, 2006) and the Cochrane Database of Systematic Reviews, issue 1, 2006. We screened previous metaanalyses and the references lists from all retrieved articles for additional studies. Further searches were carried out in two trials registers (www.clinicaltrials.gov/ and www.controlled-trials.com/) and on the web postings from conference proceedings, abstracts, and poster presentations. We also contacted authors and experts in the specialty.

\section{Study selection and data extraction}

We included published and unpublished randomised controlled trials testing the effect of oral decontamination on the incidence of pneumonia and mortality in adults requiring mechanical ventilation in an intensive care unit. We considered any type or combination of antibiotics or antiseptics. We had no language restrictions. Trials on selective decontamination of the digestive tract, observational studies, editorials, and commentaries were excluded.

Two independent reviewers (EC and AR) screened all titles and abstracts for inclusion. One reviewer (AR) was blinded to author, journal, institutional affiliation, and date of publication. We then independently assessed each selected reference for detailed evaluation. Interobserver agreement on the selection of articles for inclusion was measured with Cohen's (unweighted) $\kappa$ statistic. $^{26}$ Two reviewers (EC and AR) also independently abstracted relevant trial characteristics, and disagreements were resolved by discussion. We contacted authors of the primary studies for clarifications as necessary.

\section{Quality assessment}

Two reviewers (EC and AR) independently appraised the quality of included trials. We evaluated randomisation, allocation concealment, blinding techniques, clarity of inclusion and exclusion criteria and outcome definitions, similarity of baseline characteristics, and completeness of follow-up. We considered randomisation to be true if the allocation sequence was generated using computer programs, random number tables, or random drawing of opaque envelopes. Alternate treatment allocation was classified as non-random. Allocation was considered concealed if it involved a telephone call to a central site, used opaque sealed envelopes, or was executed centrally by the pharmacy. Allocation was categorised as unconcealed when described as open or directly managed by the study investigators or when the methods were unclear. A study was considered blinded when patients, caregivers, and data collectors or outcome assessors were blinded, or when it was reported as double blind by the authors. We contacted authors to clarify methodology as necessary.

\section{Data synthesis}

We grouped trials according to the specified prophylactic agent used for oral decontamination. The two broad categories were randomised controlled trials in which oral antibiotics were tested against no prophylaxis and oral antiseptics were tested against no prophylaxis.

The primary outcomes were incidence of ventilator associated pneumonia and mortality. We used the authors' definition for ventilator associated pneumonia if it included clinical and radiological criteria. As such, we excluded trials that used the clinical pulmonary infection score alone. We considered mortality in the intensive care unit in the absence of hospital mortality data. Secondary outcomes were the group mean duration of mechanical ventilation and stay in the intensive care unit. We also combined trials on antibiotics and antiseptics for the primary outcomes of ventilator associated pneumonia and mortality, in light of the a priori expectation of a similar magnitude and direction of treatment effect.

Meta-analysis was carried out using Review Manager 4.2 (Cochrane Collaboration, Oxford) and a random effects model. ${ }^{27}$ The pooled effects estimates for binary variables were expressed as relative risk with 95\% confidence interval, whereas continuous variables were expressed as mean differences with $95 \%$ confidence intervals. We tested the difference in estimates of treatment effect between the treatment and control groups for each hypothesis using a two sided $\mathrm{z}$ test with statistical significance considered at $\mathrm{P}<0.05$. We calculated the number of patients needed to treat (NNT, with $95 \%$ confidence interval) to prevent one episode of ventilator associated pneumonia during the period of mechanical ventilation, using the formula:

$\mathrm{NNT}=1 /(\mathrm{RRR} \times$ median $\mathrm{CER})$

where RRR is the summary relative risk reduction and median CER is the median of the control events rates for all trials.

We used Cochran $Q$ and $I^{2}$ statistics to assess for heterogeneity of results. ${ }^{2829} \mathrm{We}$ predefined heterogeneity as low, moderate, and high with $\mathrm{I}^{2}$ of above $25 \%$, $50 \%$, and $75 \%{ }^{29}$ The a priori hypotheses to explain heterogeneity were method of allocation (smaller treatment effect in concealed compared with unconcealed allocation), blinding technique (smaller treatment effect in blinded compared with unblinded studies), patient population (smaller treatment effect in medical or mixed patients compared with selected surgical or trauma patients), and duration of ventilation (smaller 


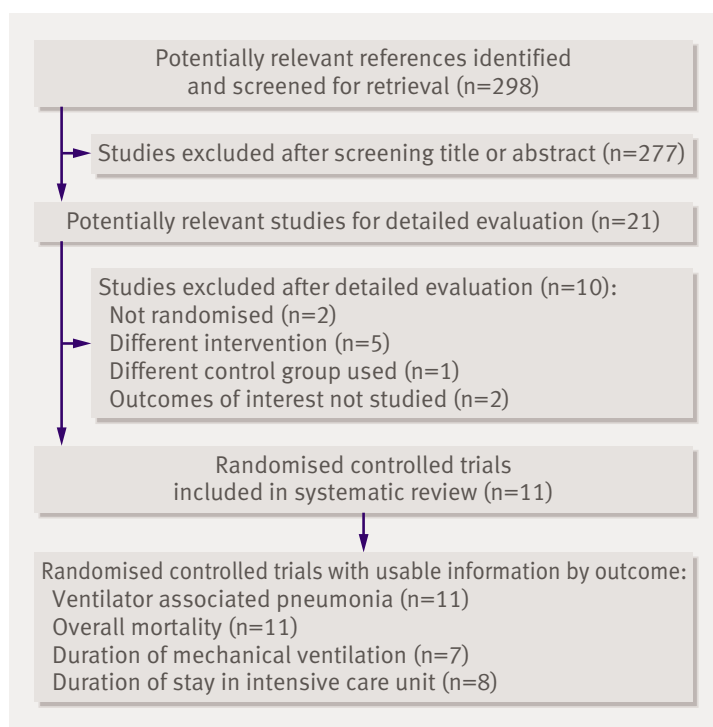

Fig 1 | Flow of studies through trial

treatment effect in patients with mean duration of ventilation of 48 hours or more compared with less than 48 hours). The purpose of the first two analyses was to evaluate whether two critical methodological qualities influenced results. ${ }^{30} \mathrm{We}$ also carried out a post hoc subgroup analysis to investigate the influence of alternative approaches to the diagnosis of ventilator associated pneumonia (quantitative culture of bronchoalveolar lavage fluid or protected specimen brush compared with non-quantitative culture of endotracheal aspirate or other criteria).

We compared relative risk estimates between subgroups using a two sided $\mathrm{z}$ test on the log relative risks, and expressed as a ratio of relative risks with its $95 \%$ confidence interval. ${ }^{31}$

The three trials with three arm comparisons were analysed as follows. In two studies, ${ }^{\text {w1 w8 }}{ }^{\text {owing to the }}$ similarity of the control arms, we pooled them and compared the results with the treatment group. In the third study ${ }^{\mathrm{w} 7}$ we excluded one of the two control arms from analysis because it incorporated both antibiotics and chlorhexidine.

To evaluate potential publication bias we constructed a funnel plot for the primary outcome of ventilator associated pneumonia, using odds ratio as the measure of effect, and visually inspected it for asymmetry. We also carried out Egger's regression intercept and Begg's rank correlation tests to assess this asymmetry formally. Analysis was done using Comprehensive Meta-analysis version 2.2.040 (Biostat, Englewood, $\mathrm{NJ}$ ). We considered a one tailed $\mathrm{P}$ value of less than 0.05 as significant.

\section{RESULTS}

Eleven randomised controlled trials totalling 3242 patients met the inclusion criteria (table 1 and fig 1). Nine were reports published between 1994 and $2006,{ }^{\text {w1-w9 }}$ and two were published in abstract form. ${ }^{\text {w10w11 }}$ Four trials (1098 patients) assessed the effectiveness of antibiotic oral decontamination, whereas seven (2144 patients) evaluated the effectiveness of antiseptic oral decontamination. In the antibiotic category one trial tested Iseganan as the decontaminant. ${ }^{\text {w2 }}$ Iseganan is a synthetic variant of a porcine protegrin, which is a natural antibiotic peptide released by neutrophils in response to invasion by microbes. Details of the excluded studies are available on request. ${ }^{18} 19212332-37$

All included studies were parallel design randomised controlled trials and were published in English. Most included general mixed patients in intensive care. Nine studies compared active treatment with placebo and two ${ }^{\mathrm{w} 5} \mathrm{w} 8 \mathrm{used}$ "standard oral care" as the control. In all trials except five, ${ }^{\text {w1 }}$ w2 w4-w6 the prophylactic regimen was given until extubation. Few studies reported on confounding strategies to prevent ventilator associated pneumonia. ${ }^{38}$ Three trials mentioned semirecumbent positioning ${ }^{\mathrm{w} 1 \mathrm{w} 7 \mathrm{w} 8}$ and only one trial controlled for route of intubation and management of humidification using a ventilator circuit. ${ }^{\text {w8 }}$

The diagnostic criteria for ventilator associated pneumonia differed across trials (table 1). Several trials used quantitative microbiology to confirm ventilator associated pneumonia: three $\mathrm{e}^{\mathrm{w} 1 \mathrm{w} 2 \mathrm{w} 8}$ required a quantitative culture of bronchoalveolar lavage fluid or protected specimen brush, two used quantitative cultures of bronchoalveolar lavage fluid or endotracheal aspirate, ${ }^{\mathrm{w} 5} \mathrm{w} 6$ and one used quantitative cultures of tracheal aspirates. ${ }^{\text {w10 }}$ The other trials used either semiquantitative techniques ${ }^{\mathrm{w} 3 \mathrm{w} 7 \mathrm{w} 11}$ or did not require microbiological confirmation, ${ }^{\text {w9 }}$ whereas in one trial the criteria were unclear. ${ }^{\mathrm{w} 4}$ Except for three trials, the inclusion criteria included an anticipated duration of mechanical ventilation of 48 hours or more. Patients were ventilated for a mean duration of more than 48 hours in all but one trial. ${ }^{\mathrm{w} 9}$ Seven trials reported duration of mechanical ventilation as means and standard deviations; eight trials reported duration of stay in the intensive care unit as such. One trial ${ }^{\mathrm{wl}}$ reported both of these outcomes as median and range values; these results were not included in the pooled analyses.

Interobserver agreement on the selection of trials for potential inclusion based on reading the titles and abstracts was excellent (Cohen's unweighted $\kappa=0.84$, $95 \%$ confidence interval 0.64 to 1.03 ). Interobserver agreement on the inclusion of relevant studies after detailed evaluation was also excellent $(\kappa=1)$.

Eight of nine authors responded to our requests and provided additional information on trial design, key quality features, and outcome data. Table 2 shows the methodological quality of included trials.

\section{Primary outcomes}

\section{Ventilator associated pneumonia}

Results from 11 trials (3242 patients) were available to examine the effects of oral decontamination on rates of ventilator associated pneumonia. Meta-analysis of four trials (1098 patients) testing antibiotic oral decontamination did not show a statistically significant reduction 


\section{Table 1 | Characteristics of included trials}

\begin{tabular}{lll}
$\begin{array}{l}\text { Study } \\
\text { Bergmans } \\
2001^{\text {w1 }}\end{array}$ & Mixed & \multicolumn{1}{c}{ Intervention } \\
& & $\begin{array}{l}\text { Orabase with gentamicin, } \\
\text { colistin, and vancomycin, } 4 \\
\text { times daily until extubation, } \\
\text { death, limited to 21 days }\end{array}$
\end{tabular}
death, limited to 21 days

Comparison

Control A, placebo in intensive care unit with patients receiving topical antimicrobial prophylaxis; control B, placebo in intensive care unit with no topical antimicrobial prophylaxis

\begin{tabular}{llll}
\hline $\begin{array}{l}\text { De Riso } \\
1996^{\text {w4 }}\end{array}$ & $\begin{array}{l}\text { Cardiothoracic } \\
\text { (open heart } \\
\text { surgery) }\end{array}$ & $\begin{array}{l}\text { Chlorhexidine } 0.12 \% 15 \mathrm{ml} \\
\text { preoperatively and twice daily } \\
\text { postoperatively until discharge } \\
\text { from intensive care or death }\end{array}$ & Placebo \\
\hline $\begin{array}{l}\text { Fourrier } \\
2000^{\text {w5* }}\end{array}$ & $\begin{array}{l}\text { Medical or } \\
\text { surgical }\end{array}$ & $\begin{array}{l}\text { Chlorhexidine } 0.2 \% \text { gel three } \\
\text { times daily during stay in } \\
\text { intensive care unit until } 28 \text { days, } \\
\text { discharge from intensive care, or } \\
\text { death }\end{array}$ & Standard treatn \\
\hline Fourrier & $\begin{array}{l}60 \% \text { medical, } \\
2005^{\text {w6* }}+\end{array}$ & $\begin{array}{l}\text { Chlorhexidine 0.2\% gel three } \\
\text { times daily during stay in } \\
\text { intensive care unit until } 28 \text { days }\end{array}$ & Placebo \\
& & &
\end{tabular}

Koeman Mixed $2006^{\mathrm{w} 7}$ * Mixed
Ventilator associated pneumonia: Centers for Disease Control and Prevention criteria.

Ventilator associated pneumonia: clinical, radiological, and bacteriological investigations bronchoalveolar lavage fluid, or both. Mortality in intensive care unit

Ventilator associated pneumonia: clinical, radiological, and bacteriological investigations and quantitative culture of tracheal aspirate or bronchoalveolar lavage fluid, or both. Mortality in intensive care unit by day 28

Ventilator associated pneumonia: clinical, radiological, and bacteriological investigations and semiquantitative culture of tracheal determined if patients had ventilator associated pneumonia. Mortality in intensive care unit Mortality in hospital and quantitative culture of tracheal aspirate or aspirates. Independent adjudication committee

Until discharge from intensive Local care unit or death

Until discharge from intensive Local care unit or death

Until 28 days in intensivecare, Local, and discharge from intensive care industry unit, or death provided study drug

\section{Until extubation, discharge Local} from intensive care unit, or death ventilator associated pneumonia, death, or extubation; treatment $B$, chlorhexidine $2 \%$ and colistin four times daily

\begin{tabular}{|c|c|c|c|c|c|c|}
\hline $\begin{array}{l}\text { Kollef } \\
2006^{\mathrm{w} 2} \dagger\end{array}$ & $\begin{array}{l}83 \% \text { non- } \\
\text { trauma, } 27 \% \\
\text { trauma }\end{array}$ & $\begin{array}{l}\text { Iseganan } 3 \mathrm{ml}(9 \mathrm{mg}) \text { six times } \\
\text { daily until } 14 \text { days. Treatment } \\
\text { discontinued if patient } \\
\text { developed ventilatorassociated } \\
\text { pneumonia or was extubated }\end{array}$ & Placebo & $\begin{array}{l}\text { Ventilator associated pneumonia: clinical, } \\
\text { radiological, and bacteriological investigations, } \\
\text { including quantitative culture of bronchoalveolar } \\
\text { lavage fluid or non-directed bronchoalveolar } \\
\text { lavage fluid. Mortality in intensive care unit by } \\
\text { day } 14\end{array}$ & Until 21 days or death & Industry \\
\hline
\end{tabular}

$1994^{\text {w3 }}$ intensive care until extubation. All received Ventilator associated pneumonia: clinical and radiological investigations and positive culture of Until extubation Not reporte oral amphotericin B and ora disinfection with phenylhydragyrum boricum and hexetidine

\begin{tabular}{llll}
\hline MacNaugh- & $\begin{array}{l}\text { Medical or } \\
\text { ton }\end{array}$ & $\begin{array}{l}\text { Chlorhexidine } 0.2 \% \text { oral rinse } \\
\text { twice daily until extubation or }\end{array}$ & Placebo \\
$2004^{\text {w11* }}$ & death &
\end{tabular}
tracheal secretions. Mortality in intensive care unit

*Published and unpublished data.

†Trial stopped early.

fUnclear if clinically defined ventilator associated pneumonia or microbiology confirmed ventilator associated pneumonia. 
in ventilator associated pneumonia rates (relative risk $0.69,0.41$ to $1.18 ; \mathrm{P}=0.18 ; \mathrm{I}^{2}=59.4 \%$; fig 2 ). Pooled analysis of the seven trials ( 2144 patients) that tested the effect of antiseptic oral decontamination on ventilator associated pneumonia showed a significant reduction (relative risk $0.56,0.39$ to $0.81 ; \mathrm{P}=0.002 ; \mathrm{I}^{2}=48.2 \%$ ). The 11 trials combined favoured oral decontamination (relative risk $0.61,0.45$ to $0.82 ; \mathrm{P}<0.001 ; \mathrm{I}^{2}=52.5 \%$ ). Fourteen patients (NNT 14, 10 to 31 ) would need to receive oral decontamination with one of these methods to prevent one case of ventilator associated pneumonia.

Table 3 summarises the four a priori subgroup analyses. An informative comparison was possible for only two subgroups in the antiseptic trials, because either none or one comparison group existed for the other subgroups. Blinded trials yielded a more modest treatment effect than unblinded trials; medical or mixed populations also seemed to derive a more modest treatment effect compared with surgical or trauma patients. Table 3 also shows the post hoc subgroup analyses on diagnostic criteria for ventilator associated pneumonia where it was possible to compare the subgroups only in the antibiotics trials. Trials that used quantitative culture of bronchoalveolar lavage fluid observed a trend towards greater treatment effects compared with those that relied on less invasive diagnostic methods.

\section{Overall mortality}

Results of all 11 trials were available for the analysis of mortality (fig 3). Meta-analysis of the four trials that tested antibiotic prophylaxis found no effect on overall mortality (relative risk $0.94,0.73$ to $1.21 ; \mathrm{P}=0.63$; $\left.\mathrm{I}^{2}=34.8 \%\right)$. The pooled analysis of the seven antiseptic trials (2144 patients) also showed no effect on mortality (0.96, 0.69 to $\left.1.33 ; \mathrm{P}=0.82 ; \mathrm{I}^{2}=42.7 \%\right)$. Pooling the 11 studies produced similar results $(0.97,0.80$ to 1.18 ; $\left.\mathrm{P}=0.74 ; \mathrm{I}^{2}=34.3 \%\right)$.

\section{Duration of mechanical ventilation}

Overall seven trials (1760 patients) contributed to the analysis of duration of mechanical ventilation. Neither the pooled mean difference for prophylaxis using

\begin{tabular}{|c|c|c|c|c|c|c|c|}
\hline Study & Randomisation & $\begin{array}{l}\text { Allocation } \\
\text { concealment }\end{array}$ & Blinding & $\begin{array}{l}\text { Explicit } \\
\text { inclusion } \\
\text { and } \\
\text { exclusion } \\
\text { criteria }\end{array}$ & $\begin{array}{l}\text { Base- } \\
\text { line } \\
\text { similari- } \\
\text { ties } \ddagger\end{array}$ & $\begin{array}{l}\text { \% Patients analysed for ventilator } \\
\text { associated pneumonia divided by } \\
\text { total No of patients randomised }\end{array}$ & $\begin{array}{l}\text { Exclusions after } \\
\text { randomisation }\end{array}$ \\
\hline $\begin{array}{l}\text { Berg- } \\
\text { mans }^{\mathrm{w1}}\end{array}$ & Unclear & Executed by pharmacy & Described as double blind & Yes & Yes & 92.2 & $\begin{array}{l}\text { Early extubation or } \\
\text { death ( } 448 \text { hours) }\end{array}$ \\
\hline De Risow4 $^{\text {w4 }}$ & Computer generated list & Executed by pharmacy & $\begin{array}{l}\text { Patients, caregivers, } \\
\text { outcome assessors }\end{array}$ & Yes & Yes & Presumably 100 & Not available \\
\hline Fourrier $^{\mathrm{w} 5 \star}$ & $\begin{array}{l}\text { Computer generated list, } \\
\text { randomisation in block of } 4\end{array}$ & Unclear & Described as single blind & Yes & Yes & Presumably 100 & Not available \\
\hline Fourrier $^{w 6 *}$ & $\begin{array}{l}\text { Block randomisation } \\
\text { stratified by site }\end{array}$ & $\begin{array}{l}\text { Sealed envelopes by } \\
\text { pharmacy }\end{array}$ & Described as double blind & Yes & Yes & 99.6 & $\begin{array}{l}\text { Protocol violation: oral } \\
\text { topical antibiotherapy } \\
\text { needed }\end{array}$ \\
\hline Koeman $^{\text {w7* }}$ & $\begin{array}{l}\text { Computer randomised } \\
\text { tables stratified by centre }\end{array}$ & Executed by pharmacy & $\begin{array}{l}\text { Patients, caregivers, data } \\
\text { collectors, outcome } \\
\text { assessors }\end{array}$ & Yes & Yes & 100 & None \\
\hline Kollef $^{\mathrm{w} 2}$ & Computer generated list & Central telephone & $\begin{array}{l}\text { Patients, caregivers, data } \\
\text { collectors, outcome } \\
\text { assessors }\end{array}$ & Yes & Yes & $\begin{array}{l}97.8 \text { (only } 87.7 \text { completed the study. } \\
\text { Unclear if those withdrawn, missing, or } \\
\text { lost to follow-up were evaluated for } \\
\text { ventilator associated pneumonia) }\end{array}$ & $\begin{array}{l}\text { Did not receive study } \\
\text { drug }\end{array}$ \\
\hline Laggner $^{\text {w3 }}$ & $\begin{array}{l}\text { Computer generated } \\
\text { randomisation in time } \\
\text { blocks† }\end{array}$ & Open & Described as double blind & Yes & Yes & 76.1 & $\begin{array}{l}\text { Early extubation ( } \\
5 \text { days), enteral } \\
\text { nutrition }\end{array}$ \\
\hline $\begin{array}{l}\text { Macnaugh- } \\
\text { ton }^{\text {w11* }}\end{array}$ & $\begin{array}{l}\text { Block randomisation by } \\
\text { random table }\end{array}$ & Executed by pharmacy & $\begin{array}{l}\text { Described as double blind } \\
\text { (patients, caregivers, } \\
\text { investigators) }\end{array}$ & Yes & Unclear & 100 & None \\
\hline $\operatorname{Rios}^{w 10 *}$ & $\begin{array}{l}\text { Random opening of opaque } \\
\text { envelopes }\end{array}$ & Executed by pharmacy & $\begin{array}{l}\text { Patients, caregivers, data } \\
\text { collectors, outcome } \\
\text { assessors }\end{array}$ & Yes & Yes & 82.8 & $\begin{array}{l}\text { Decision to limit } \\
\text { therapeutic efforts, } \\
\text { death, or early } \\
\text { extubation }\end{array}$ \\
\hline Segers $^{\mathrm{w} 9 *}$ & Computer randomised list & Executed by pharmacy & $\begin{array}{l}\text { Patients, caregivers, data } \\
\text { collectors, outcome } \\
\text { assessors }\end{array}$ & Yes & Yes & 96.3 & $\begin{array}{l}\text { Selective } \\
\text { decontamination of } \\
\text { digestive tract, } \\
\text { withdrew consent, } \\
\text { surgery cancelled or } \\
\text { death before surgery }\end{array}$ \\
\hline Seguin ${ }^{w 8 *}$ & Computer randomised list & Sealed envelopes & $\begin{array}{l}\text { Data collectors, outcome } \\
\text { assessors }\end{array}$ & Yes & Yes & 89.1 & $\begin{array}{l}\text { Brain death, early } \\
\text { extubation }\end{array}$ \\
\hline
\end{tabular}

*Published and unpublished data.

†Information obtained from Liberati et al. ${ }^{14}$

$\ddagger$ Age, sex, severity of disease, and, where available, systemic antibiotic treatment and ulcer prophylaxis usage. 


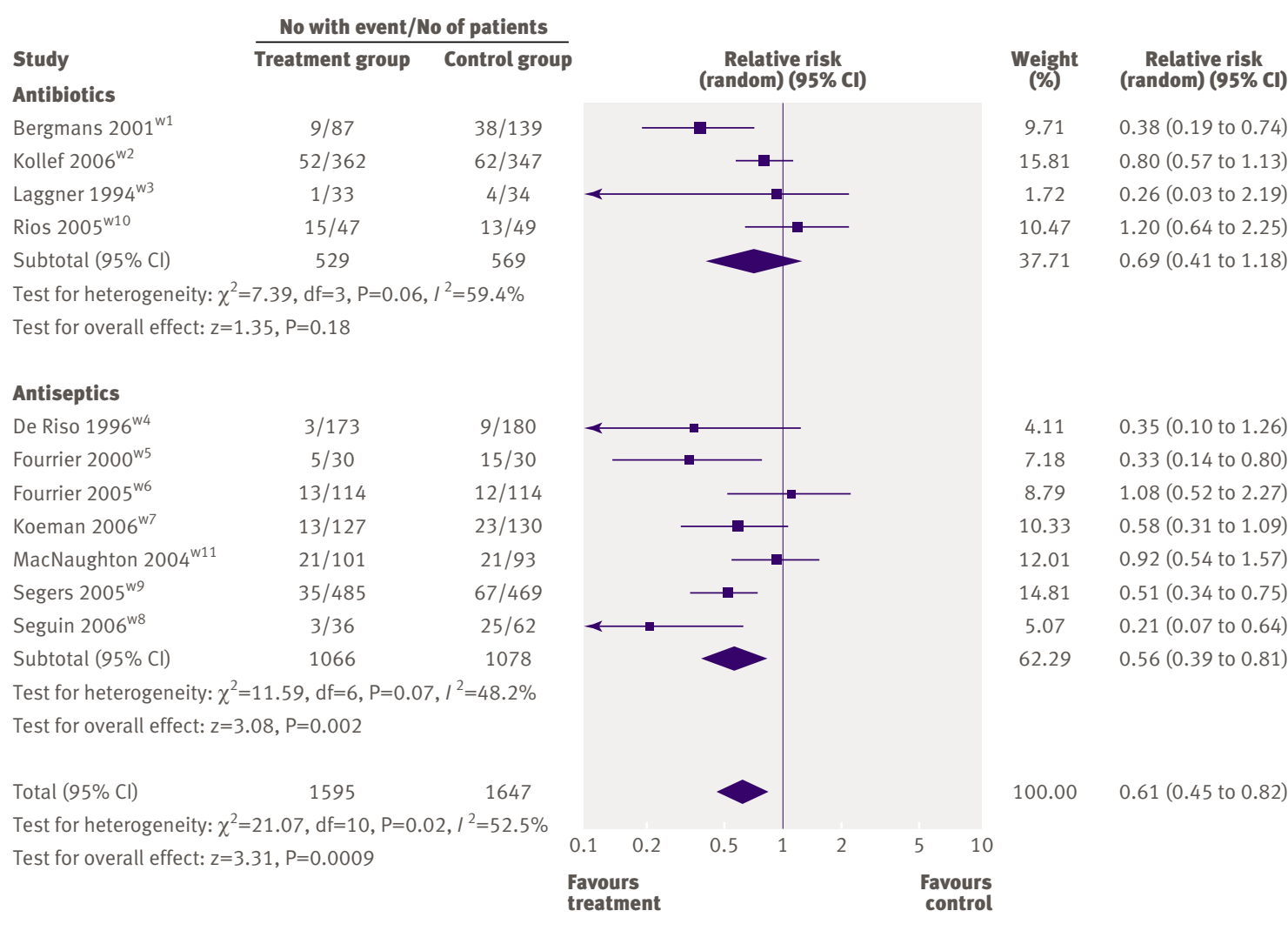

Fig 2 | Forest plot showing effect of oral decontamination prophylaxis compared with no prophylaxis on risk of ventilator associated pneumonia

antibiotics $\left(-4.02\right.$ days, -9.43 to $\left.1.40 ; \mathrm{P}=0.15 ; \mathrm{I}^{2}=0 \%\right)$ or antiseptics (0.24 days, -1.01 to $1.48 ; \mathrm{P}=0.71$; $\mathrm{I}^{2}=40.4 \%$ ) showed an effect on duration of mechanical ventilation. The combined mean difference for all trials was 0.04 days ( -1.15 to $1.23 ; \mathrm{P}=0.95 ; \mathrm{I}^{2}=31.6 \%$; fig 4$)$.

\section{Duration of stay in intensive care unit}

Overall eight trials (2113 patients) contributed to the analysis of the duration of stay in the intensive care unit, which did not seem to be influenced by prophylaxis using either antibiotics (2.30 days, -4.10 to 8.69 ; $\left.\mathrm{P}=0.48 ; \mathrm{I}^{2}=0 \%\right)$ or antiseptics $(-0.30$ days, -0.78 to $\left.0.19 ; \mathrm{P}=0.23 ; \mathrm{I}^{2}=83.5 \%\right)$. The combined mean difference for all trials was -0.28 days $(-0.76$ to 0.19 ; $\mathrm{P}=0.24 ; \mathrm{I}^{2}=77.8 \%$; fig 4 ).

\section{Publication bias}

The funnel plot for ventilator associated pneumonia was asymmetrical, suggesting the existence of unpublished small studies with negative findings (fig 5). Formal statistical tests did not, however, support the presence of publication bias: Egger's regression intercept (intercept $-1.32,-3.59$ to 0.95 ; one tailed $\mathrm{P}=0.111$ ) and Begg's rank correlation (Kendall's $\tau$ with continuity correction -0.22 ; one tailed $\mathrm{P}=0.175$ ).

\section{DISCUSSION}

The effectiveness of prophylactic oral decontamination to prevent pneumonia in patients undergoing mechanical ventilation has remained controversial since its introduction, due partly to discordant results of individual trials. We analysed antibiotic and antiseptic prophylaxis as two distinct approaches to oral decontamination. Our results suggest that antiseptic oral decontamination is effective at preventing ventilator associated pneumonia. More evidence is needed before firm conclusions can be made about antibiotic oral decontamination, although effects may be similar. This review included twice as many participants in the antiseptic trials than antibiotic trials, reflecting more precise results for the analysis of antiseptics.

We found that neither antibiotic nor antiseptic oral decontamination influenced overall mortality, duration of mechanical ventilation, or duration of stay in an intensive care unit. Our review was underpowered to detect any effect on mortality, and the small sample size limited the interpretation of the secondary outcomes.

\section{Comparison with previous studies}

Previous meta-analyses examining the effect of prophylaxis using selective decontamination of the digestive tract reported a significant reduction in the incidence of ventilator associated pneumonia. ${ }^{6-14}$ The most recent meta-analysis indicated that such an intervention combined with prophylactic intravenous antibiotics reduces overall mortality. ${ }^{14}$ In comparison our review suggests that oral antiseptic prophylaxis alone 


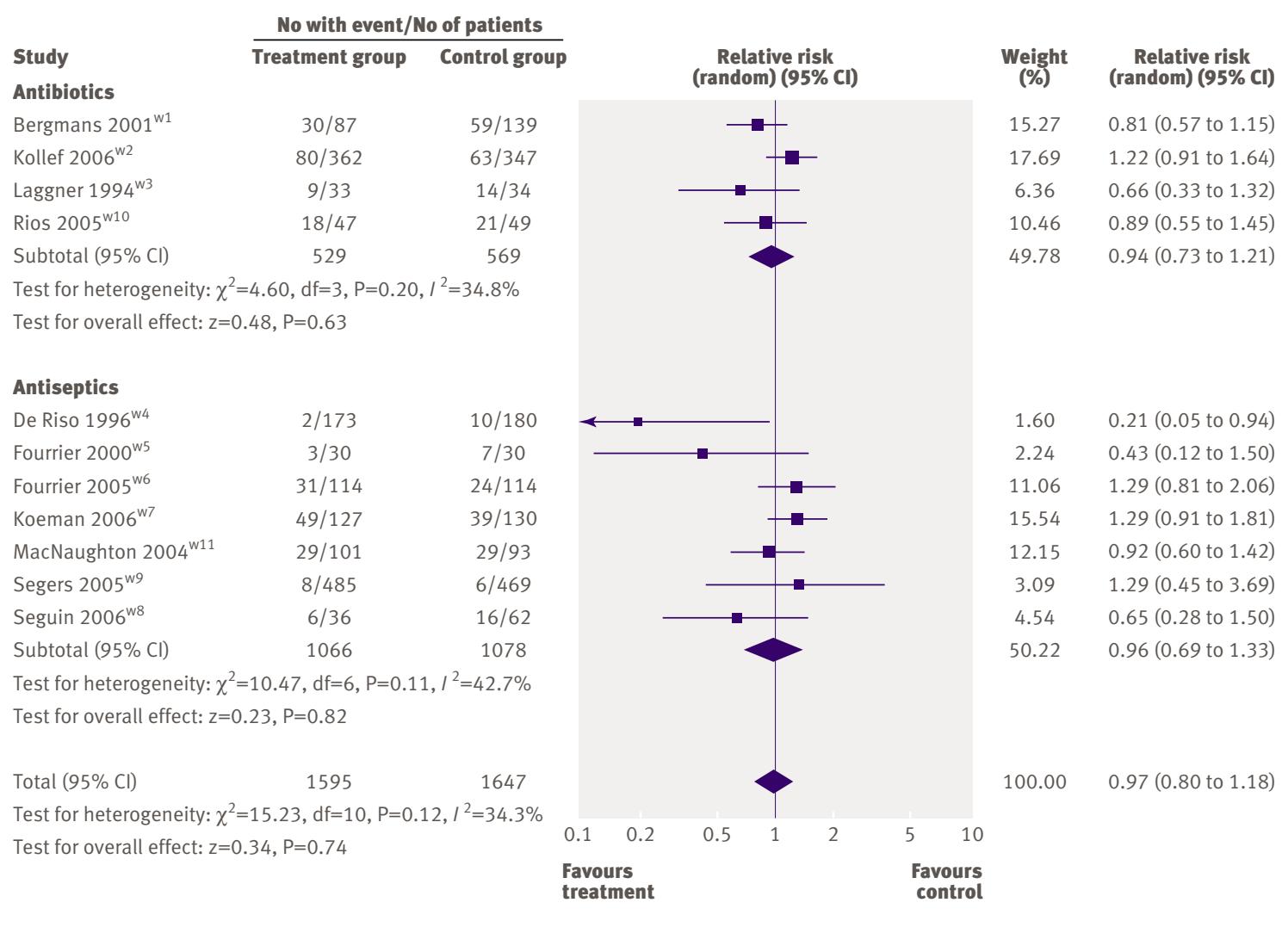

Fig 3 | Forest plot showing effect of oral decontamination prophylaxis compared with no prophylaxis on overall mortality

can significantly reduce the incidence of ventilator associated pneumonia, but not mortality. Our metaanalysis on antiseptics differs from the findings of Pineda et al, who pooled four trials on chlorhexidine and did not report lower rates of ventilator associated pneumonia (odds ratio $0.42,0.16-1.06 ; \mathrm{P}=0.07) .{ }^{24} \mathrm{Our}$ results also extend those of Chlebicki et al, who did not find a statistically significant benefit using the more conservative random effects model after pooling seven trials on chlorhexidine (relative risk 0.70, 0.471.04; $\mathrm{P}=0.07)$, although their results were significant with the fixed effects model. ${ }^{39}$ Our systematic review included a larger dataset with two more recent trials, ${ }^{\text {w8 }}{ }^{9}$ involved clarification of data from several authors, and explored heterogeneity with more subgroup analyses.

\section{Possible explanations and implications}

The lack of effect on secondary outcomes may raise concern about the accuracy with which ventilator associated pneumonia was diagnosed, given that the antiseptic trials, despite showing a substantial reduction in ventilator associated pneumonia rates, failed to show similar benefit for these secondary outcomes. It is possible that the combination of clinical, radiological, and microbiological criteria without the use of quantitative investigations using cultures of bronchoalveolar lavage fluid, which may have a high sensitivity but low specificity, ${ }^{40}$ may contribute to an overestimation of the ventilator associated pneumonia rates in these trials, and a greater observed treatment effect.

To ensure that the lack of effect on patients' secondary outcomes did not arise from the differences in the diagnostic criteria used by the primary trials, we carried out a post hoc subgroup analysis on the basis of diagnostic criteria for ventilator associated pneumonia (differentiating between trials using invasive quantitative culture of bronchoalveolar lavage fluid or protected specimen brush versus other less invasive approaches). Only one of the antiseptic trials used invasive quantitative criteria, rendering further analysis not possible. Our analysis for the antibiotic trials was inconclusive, showing a trend towards a greater treatment effect for the trials that used the more invasive diagnostic criteria (table 3 ). An analysis combining all trials on antibiotics and antiseptics also suggested the same trend (invasive quantitative criteria's relative risk $0.45,0.21$ to $0.98 v$ less invasive criteria's relative risk $0.66,0.47$ to 0.93 ), although the comparison of these relative risks was not conclusive (ratio of relative risks $0.68,0.29$ to $1.58 ; \mathrm{P}=0.37)$. Nevertheless, a recent large multicentre trial found no difference in clinical outcomes or subsequent overall antibiotic use when a diagnostic approach of quantitative culture of bronchoalveolar lavage fluid was compared with non-quantitative culture of endotracheal aspirate among nonimmunocompromised patients not suspected of harbouring high risk organisms. ${ }^{41}$ 
Our a priori subgroup analyses suggest that trials with an unblinded design and those enrolling surgical or trauma patients tended to yield qualitatively larger treatment effects than blinded trials and those enrolling medical or mixed critically ill patients. The former result is consistent with previous work showing that trials of lower methodological quality tend to report greater treatment effects. ${ }^{42}$ Specific surgical or trauma patients often have fewer comorbidities than medical or mixed patients, which may explain the trend towards a greater treatment effect in the former population. However, these subgroup results are best viewed as hypothesis generating.

The finding that antiseptic oral decontamination can reduce the incidence of ventilator associated pneumonia could have important implications for lower healthcare costs and a reduced risk of antibiotic resistance compared with the use of antibiotics. It may not be prudent to adopt this practice routinely for all critically ill patients until strong data on the long term risk of selecting antiseptic and antibiotic resistant organisms are available. Nevertheless, antiseptic oral decontamination seems promising.

\section{Strengths and weaknesses of the study}

The strengths of this review include the comprehensive search for relevant randomised controlled trials, duplicate screening, selection, assessment of methodological quality and data abstraction, and use of the random effects model (which takes heterogeneity into account) to combine trial results. We separated and then combined the antibiotic and antiseptic trials, anticipating that the underlying pathophysiology could lead to a similar treatment effect across the trials, ${ }^{43}$ and because an overall treatment effect is of interest in examining the relation between oral flora and lung infection during critical illness.

We inspected funnel plots to evaluate potential publication bias for ventilator associated pneumonia. We also undertook formal statistical tests. These did not show the presence of publication bias for the combined 11 antibiotics and antiseptic trials. However, the power of these tests is generally low. Although our literature search was comprehensive, it is possible that we missed other relevant trials. In addition, these trials were heterogeneous with respect to populations enrolled, regimens used, outcome definitions, and analysis strategies, contributing to differing relative risks across the trials. Other limitations of the trials we included were exclusions after randomisation, mainly due to early extubation, early deaths, or protocol violations. Some trials did not explicitly report whether the number of patients analysed reflected the total number of patients randomised (table 2) such that we were unable to abstract the intention to treat analyses from all trials. Finally, we could not obtain unpublished data from some authors on the mean duration of mechanical ventilation and stay in an intensive care unit.

\section{Unanswered questions and future research}

Our systematic review supports the use of antiseptic oral decontamination. Research to date does not

\begin{tabular}{|c|c|c|c|c|c|c|}
\hline \multirow[b]{2}{*}{ Measurement } & \multicolumn{3}{|c|}{ Antibiotic oral decontamination } & \multicolumn{3}{|c|}{ Antiseptic oral decontamination } \\
\hline & Relative risk $(95 \% \mathrm{Cl})$ & $\begin{array}{l}\text { No of studies (No } \\
\text { of patients) }\end{array}$ & $\begin{array}{l}\text { Ratio of relative risks }(95 \% \\
\text { (I), } \mathrm{P} \text { value* }\end{array}$ & Relative risk $(95 \% \mathrm{Cl})$ & $\begin{array}{l}\text { No of studies (No } \\
\text { of patients) }\end{array}$ & $\begin{array}{l}\text { Ratio of relative risks }(95 \% \\
\text { CI); } \text { v value }^{\star}\end{array}$ \\
\hline \multicolumn{7}{|l|}{ Allocation: } \\
\hline Concealed $†$ & 0.73 (0.42 to 1.28$)$ & $3(1031)$ & \multirow[t]{2}{*}{-} & 0.60 (0.40 to 0.89$)$ & $6(2084)$ & \multirow[t]{2}{*}{-} \\
\hline Unconcealed & $0.26(0.03$ to 2.19$)$ & $1(67)$ & & $0.33(0.14$ to 0.80$)$ & $1(60)$ & \\
\hline \multicolumn{7}{|l|}{ Blinding: } \\
\hline Blinded $\ddagger$ & - & - & \multirow[t]{2}{*}{ NA§ } & $0.66(0.47$ to 0.93$)$ & $5(1986)$ & \multirow[t]{2}{*}{2.36 (1.09 to 5.10$) ; 0.03$} \\
\hline Unblinded & - & - & & $0.28(0.14$ to 0.56$)$ & $2(158)$ & \\
\hline \multicolumn{7}{|l|}{ Patient population: } \\
\hline Medical or mixed & - & - & \multirow[t]{2}{*}{ NAT } & $0.70(0.44$ to 1.10$)$ & $4(739)$ & \multirow[t]{2}{*}{1.67 (0.86 to 3.22$) ; 0.13$} \\
\hline Selected surgical or trauma & - & - & & $0.42(0.26$ to 0.67$)$ & $3(1405)$ & \\
\hline \multicolumn{7}{|l|}{ Duration of ventilation (hours): } \\
\hline$\geq 48$ & - & - & \multirow[t]{2}{*}{$N A^{\star \star}$} & $0.56(0.34$ to 0.91$)$ & $6(1190)$ & \multirow[t]{2}{*}{-} \\
\hline$<48$ & - & - & & $0.51(0.34$ to 0.75$)$ & $1(954)$ & \\
\hline $\begin{array}{l}\text { Ventilator associated } \\
\text { pneumonia diagnostic criteria: }\end{array}$ & & & & & & - \\
\hline $\begin{array}{l}\text { Quantitative culture of } \\
\text { bronchoalveolar lavage fluid }\end{array}$ & $0.58(0.28$ to 1.22$)$ & $2(935)$ & \multirow[t]{2}{*}{0.74 (0.16 to 3.53); $P=0.71$} & 0.21 (0.07 to 0.64$)$ & $1(98)$ & \multirow[t]{2}{*}{-} \\
\hline $\begin{array}{l}\text { Non-quantitative culture of } \\
\text { aspirate or others }\end{array}$ & $0.78(0.20$ to 3.12$)$ & $2(163)$ & & 0.61 (0.44 to 0.86$)$ & $6(2046)$ & \\
\hline
\end{tabular}

*Comparison of estimates in each subgroup (for example, concealed versus unconcealed trials).

tConcealed $=$ reported as open, or unclear.

$\ddagger$ Patients, caregivers, and data collectors or outcome assessors blinded, or reported as double blind.

$\S$ None were unblinded.

TNone were surgical or trauma patients.

**None were ventilated for $<48$ hours. 


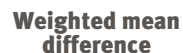
difference

(random) $(95 \% \mathrm{Cl})$ $\begin{array}{cc}\text { Weight } & \begin{array}{c}\text { Weighted mean } \\ \text { difference } \\ \text { (\%) }\end{array} \\ \text { (random) }(95 \% \mathrm{Cl})\end{array}$

Duration of mechanical ventilation

Antibiotics

$\begin{array}{llcc}\text { Laggner } 1994^{\mathrm{w} 3} & 33 & 15.80(11.10) & 34 \\ \text { Rios } 2005^{\mathrm{w} 10} & 47 & 12.00(11.00) & 49 \\ \text { Subtotal }(95 \% \mathrm{Cl}) & 80 & & 83 \\ \text { Test for heterogeneity: } \chi^{2}=0.00, \mathrm{df}=1, \mathrm{P}=0.99, I^{2}=0 \% \\ \text { Test for overall effect: } \mathrm{z}=1.45, \mathrm{P}=0.15\end{array}$

Antiseptics

Fourrie $2(40)$

Fourrier $2005^{\mathrm{w} 6}-114 \quad 11.70(8.70)$

Koeman $2006^{\mathrm{w} 7} \quad 127 \quad 9.16(12.00)$

30

114

$18.00(20.00)$

130

$10.60(8.70)$

$6.95(8.10)$

Segers $2005^{\text {w9 }} \quad 485$

$0.51(0.55)$

469

$0.56(0.79)$

Seguin $2006^{\text {w8 }} \quad 36$

$9.00(8.00)$

62

$11.00(8.86)$

Subtotal $(95 \% \mathrm{Cl}) 792$

805

Test for heterogeneity: $\chi^{2}=6.71, \mathrm{df}=4, \mathrm{P}=0.15, I^{2}=40.4 \%$

Test for overall effect: $z=0.37, P=0.71$

Total $(95 \% \mathrm{Cl})$

872

888

Test for heterogeneity: $\chi^{2}=8.77, \mathrm{df}=6, \mathrm{P}=0.19, I^{2}=31.6 \%$

$19.90(37.50)$

Test for overall effect: $z=0.07, P=0.95$

Duration of stay in intensive care unit

Antibiotics

Laggner $1994^{\mathrm{w} 3} \quad 33 \quad 24.90(16.20)$

Rios $2005^{\mathrm{w} 10} \quad 47 \quad 19.00(18.00) \quad 49$

34

$31.50(68.30)$

Subtotal $(95 \% \mathrm{Cl}) \quad 80$

$16.00(15.00)$

Test for heterogeneity: $\chi^{2}=0.59, \mathrm{df}=1, \mathrm{P}=0.44, I^{2}=0 \%$

Test for overall effect: $\mathrm{z}=0.70, \mathrm{P}=0.48$

\section{Antiseptics}

De Riso $1966^{\text {w4 }}$

Fourrier $2000^{\mathrm{w} 5}$

Fourrier $2005^{\mathrm{w} 6} \quad 114$

173

$7.90(0.61)$

180

$18.00(16.00)$

Fourrier $2005^{\mathrm{w}}$

14

$14.00(8.50)$

$13.77(17.40)$

Segers $2005^{\mathrm{w} 9} \quad 485$

1.21 (1.07)

$15.00(14.00)$

Seguin $2006^{\text {w8 }} \quad 36$

Subtotal $(95 \%$ Cl) 965

$15.00(14.00)$

Test for heterogeneity: $\chi^{2}=30.25, \mathrm{df}=5, \mathrm{P}<0.0001, I^{2}=83.5 \%$

Test for overall effect: $z=1.20, P=0.23$

Total $(95 \% \mathrm{Cl}) \quad 1045$

1068

Test for heterogeneity: $\chi^{2}=31.51, \mathrm{df}=7, \mathrm{P}<0.0001, I^{2}=77.8 \%$

Test for overall effect: $z=1.16, P=0.24$
$11413.30(8.80)$

$13012.45(12.90)$

$6216.50(13.58)$ 985 $3.5 \%$ 5
$469 \quad 1.29(1.29)$

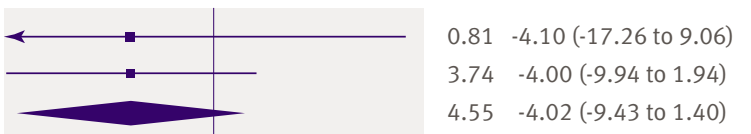

$4.55-4.02(-9.43$ to 1.40$)$

$1.97-5.00(-13.35$ to 3.35$)$

$17.97 \quad 1.10$ (-1.16 to 3.36$)$

$15.622 .21(-0.30$ to 4.72$)$

$50.06-0.05$ (-0.14 to 0.04$)$

$9.82-2.00(-5.42$ to 1.42$)$

95.450 .24 (-1.01 to 1.48$)$

100.000 .04 (-1.15 to 1.23$)$

Fig 4 | Forest plot showing effect of oral decontamination prophylaxis compared with no prophylaxis on duration (days) of mechanical ventilation and duration of stay (days) in an intensive care unit

address which antiseptic is preferred, since all but one trial evaluated chlorhexidine. We cannot recommend precise methods for chlorhexidine administration owing to the wide variation of treatment regimens among studies. These included varying concentrations $(0.12 \%, 0.2 \%, 2 \%)$, sites of application, forms of agent (oral rinse, gel), and frequencies and techniques of application. Nevertheless, our findings suggest that the concentration of chlorhexidine may be a consideration. In trials with cardiac surgery patients at low risk for developing ventilator associated pneumonia owing to a short duration of intubation, chlorhexidine $0.12 \%$ was effective in reducing ventilator associated pneumonia. $^{\text {w4 w9 }}$ However, among medical or mixed intensive care populations, a higher concentration may be necessary. Chlorhexidine was not effective in most of these trials at $0.2 \%$ concentration $^{\mathrm{w} 6 \mathrm{w} 11}$ but was effective at $2 \%{ }^{\mathrm{w} 7}$ As for the only trial that used povidone iodine, the agent was found to be effective in preventing ventilator associated pneumonia among 98 


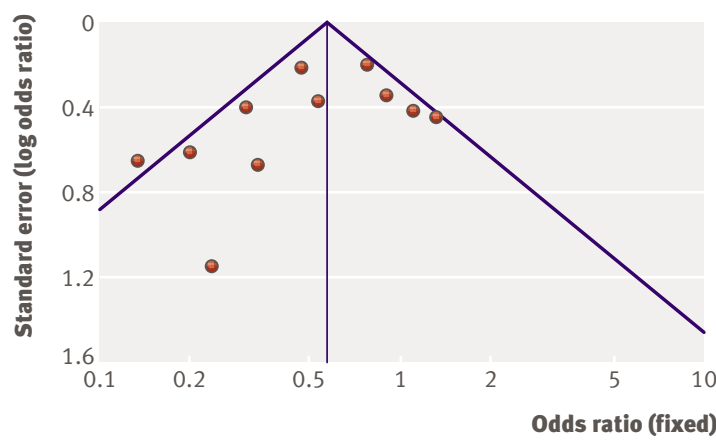

Fig 5 | Funnel plots assessing publication bias for ventilator associated pneumonia

patients with head injuries with a persistent score of 8 or less on the Glasgow coma scale requiring mechanical ventilation for 48 hours or more. ${ }^{\text {w8 }}$

To our knowledge no trial directly compares antiseptic with antibiotic oral decontamination. Further investigations comparing antibiotic with antiseptic oral decontamination while incorporating stringent infection surveillance would be worthwhile. Whether either antibiotic or antiseptic oral decontamination favourably influence important patient outcomes such as duration of mechanical ventilation or duration of stay in the intensive care unit should be evaluated in rigorously designed and adequately powered randomised trials.

\section{CONCLUSIONS}

This systematic review suggests that in mechanically ventilated patients, antiseptic oral decontamination prophylaxis reduces the incidence of ventilator associated pneumonia. More evidence is needed before firm conclusions can be made on the effect of antibiotic oral decontamination. These results should be interpreted in light of the moderate heterogeneity of trial results and possible publication bias. Neither of these two approaches to decontamination seems to affect mortality, duration of mechanical ventilation, or stay in the intensive care unit, although these trials are underpowered for these latter outcomes, and the summary of trials to date does not yet represent the optimum information size. ${ }^{44}$ Therefore more evidence is needed before firm conclusions can be made on the

\section{WHAT IS ALREADY KNOWN ON THIS TOPIC}

Selective decontamination of the digestive tract reduces the incidence of ventilator associated pneumonia

Oral decontamination requires only a fraction of the antibiotics used for selective

decontamination

\section{WHAT THIS STUDY ADDS}

Oral decontamination using antiseptics reduces the incidence of ventilator associated pneumonia

Neither antibiotic nor antiseptic oral decontamination reduces overall mortality or duration of mechanical ventilation or stay in intensive care full effect of oral decontamination using antiseptics and, particularly, antibiotics.

We thank Patrique Segers, Mirelle Koeman, Carlos Apezteguia, Fernando Rios, Peter Macnaughton, Francois Fourrier, Philippe Seguin, and José Manuel Rodriguez-Roldan for providing additional information on their trials.

Contributors: All authors contributed to the concept, design, and critical revision of the manuscript. EC and AR carried out the search, selected the articles, and extracted the data. EC carried out the statistical analyses with input from AR, drafted the review, and is guarantor.

Funding: EC is supported by a scholarship award from Tan Tock Seng Hospital and National Healthcare Group HMDP, Singapore. AR is supported by a postdoctoral fellowship award from the Fonds de Recherche en Santé du Québec and from Université Laval. DJC holds a Canada Research Chair. Statement of the independence of researchers from funders: The authors' work was independent of the funders (the funding source has no involvement).

Competing interests: None declared.

Ethical approval: Not required.

1 Chastre J, Fagon JY. Ventilator-associated pneumonia. Am J Respir Crit Care Med 2002;165:867-903.

2 Rello J, Ollendorf DA, Oster G, Vera-Llonch M, Bellm L, Redman R, et al. Epidemiology and outcomes of ventilator-associated pneumonia in a large US database. Chest 2002;122:2115-21.

3 Tablan OC, Anderson LJ, Besser R, Bridges C, Hajjeh R. Guidelines for preventing health-care-associated pneumonia, 2003. recommendations of $C D C$ and the Healthcare Infection Control Practices Advisory Committee. MMWR Recomm Rep 2004;53:1-36.

4 American Thoracic Society, Infectious Diseases Society of America. Guidelines for the management of adults with hospital-acquired, ventilator-associated, and healthcare-associated pneumonia. Am J Respir Crit Care Med 2005;171:388-416.

5 Estes RJ, Meduri GU. The pathogenesis of ventilator-associated pneumonia: I. Mechanisms of bacterial transcolonisation and airway inoculation. Intensive Care Med 1995;21:365-83.

6 Stoutenbeek CP, van Saene HK, Miranda DR, Zandstra DF. The effect of selective decontamination of the digestive tract on colonisation and infection rate in multiple trauma patients. Intensive Care Med 1984;10:185-92.

7 Vandenbroucke-Grauls CM, Vandenbroucke JP. Effect of selective decontamination of the digestive tract on respiratory tract infections and mortality in the intensive care unit. Lancet 1991;338:859-62.

8 Selective Decontamination of the Digestive Tract Trialists' Collaborative Group. Meta-analysis of randomised controlled trials of selective decontamination of the digestive tract. $B M J$ 1993;307:525-32.

9 Heyland DK, Cook DJ, Jaeschke R, Griffith L, Lee HN, Guyatt GH. Selective decontamination of the digestive tract. An overview. Chest 1994;105:1221-9.

10 Kollef $\mathrm{MH}$. The role of selective digestive tract decontamination on mortality and respiratory tract infections. A meta-analysis. Chest 1994;105:1101-8.

11 Hurley JC. Prophylaxis with enteral antibiotics in ventilated patients: selective decontamination or selective cross-infection? Antimicrob Agents Chemother 1995;39:941-7.

12 D’Amico R, Pifferi S, Leonetti C, Torri V, Tinazzi A, Liberati A. Effectiveness of antibiotic prophylaxis in critically ill adult patients: systematic review of randomised controlled trials. $B M$ J 1998;316:1275-85

13 Nathens AB, Marshall JC. Selective decontamination of the digestive tract in surgical patients: A systematic review of the evidence. Arch Surg 1999;134:170-6.

14 Liberati A, D'Amico R, Pifferi, Torri V, Brazzi L. Antibiotic prophylaxis to reduce respiratory tract infections and mortality in adults receiving intensive care. Cochrane Database Syst Rev 2004;(1):CD000022.

15 Kollef MH. Opinion: the clinical use of selective digestive decontamination. Crit Care 2000;4:327-32.

16 Gastinne $\mathrm{H}$, Wolff $M$, Delatour F, Faurisson F, Chevret S. A controlled trial in intensive care units of selective decontamination of the digestive tract with nonabsorbable antibiotics. The French Study Group on Selective Decontamination of the Digestive Tract. N Engl Med 1992;326:594-9.

17 Brun-Buisson C, Legrand P, Rauss A, Richard C, Montravers F, Besbes M, et al. Intestinal decontamination for control of nosocomial multiresistant gram-negative bacilli. Study of an outbreak in an intensive care unit. Ann Intern Med 1989;110:873-81.

18 Abele-Horn M, Dauber A, Bauernfeind A, Russwurm W, Seyfarth-Metzger I, Gleich P, et al. Decrease in nosocomial pneumonia in ventilated patients by selective oropharyngeal decontamination (SOD). Intensive Care Med 1997;23:187-95. 
19 Rodriguez-Roldan JM, Altuna-Cuesta A, Lopez A, Carrillo A, Garcia J, Leon J, et al. Prevention of nosocomial lung infection in ventilated patients: use of an antimicrobial pharyngeal nonabsorbable paste. Crit Care Med 1990;18:1239-42.

20 Pittet D. Improving compliance with hand hygiene. In: Wenzel RP, ed Prevention and control of nosocomial infections, 4th ed. Philadelphia: Lippincott Williams, and Wilkins, 2003:532-3.

21 Genuit T, Bochicchio G, Napolitano LM, McCarter RJ, Roghman MC. Prophylactic chlorhexidine oral rinse decreases ventilatorassociated pneumonia in surgical ICU patients. Surg Infect (Larchmt) 2001;2:5-18.

22 Mori H, Hirasawa H, Oda S, Shiga H, Matsuda K, Nakamura M. Oral care reduces incidence of ventilator-associated pneumonia in ICU populations. Intensive Care Med 2006;32:230-6.

23 Houston S, Hougland P, Anderson JJ, LaRocco M, Kennedy V, Gentry LO. Effectiveness of $0.12 \%$ chlorhexidine gluconate oral rinse in reducing prevalence of nosocomial pneumonia in patients undergoing heart surgery. Am J Crit Care 2002;11:567-70.

24 Pineda LA, Saliba RG, El Solh AA. Effect of oral decontamination with chlorhexidine on the incidence of nosocomial pneumonia: a metaanalysis. Crit Care 2006;10:R35.

25 Rello J, Koulenti D, Blot S, Sierra R, Diaz E, De Waale J, et al. Oral care practices in intensive care units. A survey of 59 European intensive care units. Intensive Care Med (In press).

26 Fleiss J.L., Cohen J. The equivalence of weighed kappa and the intraclass correlation coefficient as measures of realibility. Educ Psychol Meas 1973;33:613-9.

27 DerSimonian R, Laird N. Meta-analysis in clinical trials. Control Clin Trials 1986;7:177-88.

28 Higgins JP, Thompson SG. Quantifying heterogeneity in a metaanalysis. Stat Med 2002;21:1539-58.

29 Higgins JP, Thompson SG, Deeks JJ, Altman DG. Measuring inconsistency in meta-analyses. BMJ 2003;327:557-60.

30 Moher D, Pham B, Jones A, Cook DJ, Jadad AR, Moher M, et al. Does quality of reports of randomised trials affect estimates of intervention efficacy reported in meta-analyses? Lancet 1998;352:609-13.

31 Altman DG, Bland JM. Interaction revisited: the difference between two estimates. BMJ 2003;326:219.

32 Camus C, Bellissant E, Sebille V, Perrotin D, Garo B, Legras A, et al. Prevention of acquired infections in intubated patients with the combination of two decontamination regimens. Crit Care Med 2005;33:307-14

33 Grap MJ, Munro CL, Elswick RK Jr, Sessler CN, Ward KR. Duration of action of a single, early oral application of chlorhexidine on oral microbial flora in mechanically ventilated patients: a pilot study. Heart Lung 2004;33:83-91.

34 Kerver AJ, Rommes JH, Mevissen-Verhage EA, Hulstaert PF, Vos A Verhoef J, et al. Prevention of colonization and infection in critically ill patients: a prospective randomised study. Crit Care Med 1988;16:1087-93.

35 Ogata J, Minami K, Miyamoto H, Horishita T, Ogawa M, Sata T, et al. Gargling with povidone-iodine reduces the transport of bacteria during oral intubation. Can J Anaesth 2004;51:932-6.

36 Pugin J, Auckenthaler R, Lew DP, Suter PM. Oropharyngeal decontamination decreases incidence of ventilator-associated pneumonia. A randomised, placebo-controlled, double-blind clinical trial. JAMA 1991;265:2704-10.

37 Silvestri L, van Saene HK, Milanese M, Fontana F, Gregori D, Oblach L, et al. Prevention of MRSA pneumonia by oral vancomycin decontamination: a randomised trial. Eur Respir / 2004;23:921-6.

38 Dodek P, Keenan S, Cook D, Heyland D, Jacka M, Hand L, et al. Evidence-based clinical practice guideline for the prevention of ventilator-associated pneumonia. Ann Intern Med 2004;141:305-13.

39 Chlebicki MP, Safdar N. Topical chlorhexidine for prevention of ventilator-associated pneumonia: a meta-analysis. Crit Care Med 2007;35:595-602.

40 Pingleton SK, Fagon JY, Leeper KV Jr. Patient selection for clinical investigation of ventilator-associated pneumonia. Criteria for evaluating diagnostic techniques. Chest 1992;102(5 Suppl 1):S553-

41 Canadian Critical Care Trials Group, Heyland D, Cook DJ, Dodek P, Muscedere J, Day A. A randomised trial of diagnostic techniques for ventilator-associated pneumonia. N Engl / Med 2006;355:2619-30.

42 Schulz KF, Chalmers I, Hayes RJ, Altman DG. Empirical evidence of bias: dimensions of methodological quality associated with estimates of treatment effects in controlled trials. JAMA 1995;273:408-12.

43 Hatala R, Keitz S, Wyer P, Guyatt G, Evidence-Based Medicine Teaching Tips Working Group. Tips for learners of evidence-based medicine: 4 . Assessing heterogeneity of primary studies in systematic reviews and whether to combine their results. CMA 2005;172:661-5.

44 Devereaux PJ, Beattie WS, Choi PT, Badner NH, Guyatt GH, Villar JC, et al. How strong is the evidence for the use of perioperative beta blockers in non-cardiac surgery? Systematic review and metaanalysis of randomised controlled trials. BMJ 2005;331:313-21.

Accepted: 28 January 2007 